\title{
Using Visual Analytics to Improve Hospital Scheduling and Patient Flow
}

\author{
Janna Anneke Fitzgerald ${ }^{1}$ and Ann Dadich ${ }^{2}$ \\ University of Western Sydney, Centre for Industry and Innovation Studies \\ ${ }^{1}$ a.fitzgerald@uws.edu.au, ${ }^{2}$ a.dadich@uws.edu.au
}

Received 8 January 2009; received in revised form 24 May 2009; accepted 15 June 2009

\begin{abstract}
The increasing demand for hospital emergency services has important implications for the allocation of limited public resources and the management of healthcare services. Although reform is an oft-cited way to improve the healthcare system, it has a limited ability to readily address this increasing demand. This paper presents an innovative approach to identify and translate feasible solutions to improve the efficiency of hospitals. Premised on visual analytics, the paper describes the way a software program was used to represent sonography department processes within a virtual environment. The processes were represented by collecting and assembling information about room capacity, room use, patient-scheduling practices, staff capacity, and equipment availability. The resulting model helped to identify areas for improvement and simulate viable options to improve these areas. This was associated with two clear benefits - it allowed solutions to be considered without making changes to the physical environment, and it provided a way to clearly demonstrate to staff the relationship between process change and improved efficiency. The paper concludes with directions for future research.
\end{abstract}

Key words: Visual analytics, health services, management, innovation, emergency departments, patient flow 


\section{Introduction}

In many Western nations, the demand for hospital services is increasing [52], fuelling public concern that the healthcare system is in crisis [60], [10]. Increased demand is particularly evident within emergency departments (EDs) [13]. In Australia for instance, there were approximately 6.7 million presentations to EDs in a recent 12-month period [7] - this represents an increase of 400,000 patients from the previous year [6]. However, Australian public hospitals have a limited capacity to meet this demand [13].

The limited capacity of EDs is evidenced by access block [2], [17]. According to the Australian Council on Healthcare Standards and Australasian College for Emergency Medicine (ACHS-ACEM) [1], access block occurs when a patient remains in an ED for over eight hours, consequent to the limited availability of an inpatient bed. Although international statistics are limited, an examination of Australian data suggests that thirty to forty percent of emergency patients exceed this eight-hour limit [65]. Given that the functionality of an ED degrades once access block exceeds ten percent, this statistic constitutes a serious concern.

The consequences of access block are costly. In addition to increasing risk to patient health [71], [34], [78], it affects the allocation of limited public resources and the management of healthcare services. More specifically, it is associated with decreased efficiency in the ED [26], [27], [16], [66] and increased inpatient stays [67]. Given the interconnected nature of hospital departments, access block is likely to hinder patient flow throughout a hospital [40]. As such, it can reduce the efficiency of the surgical, intensive care, pharmaceutical, and diagnostic imaging departments, among others.

The causes of access block are multifaceted. In addition to an insufficient number of inpatient beds [2], access block is attributed to limited workforce capacity; an ageing population; the increasing number of young patients (under 25 years) who access EDs as a substitute for primary care [13], [5]; the increasing number of patients requiring intense and/or continued hospital treatment [30], thus overcrowding hospital departments [35]; a decline in community services including nursing homes and mental health services, which in turn adds further strain on the hospital system [31]; changing patient expectations, largely consequent to improved access to health information; changing referral patterns - for instance, 86 percent of patients in the Australian state of New South Wales (NSW) self-refer to EDs; increased use of ambulance services, which has risen by 10 percent annually in the last two years; the limited access of day clinics and private practitioners [62]; the decline in bulk billing among general practitioners [41], [33], [45], [42], particularly in rural areas [84], [23], [69]; and funding arrangements that focus on elective surgery and outpatient care [2].

Although there have been some attempts to improve access to hospital services - including recommendations by professional bodies [3], improvements are yet to be seen. Furthermore, some strategies may have exacerbated access block. For instance, efforts to improve the skill level of ED staff and allow access to specialists within the same ED visit may have promoted the use of EDs [13].

The systemic nature of the aforesaid problems is likely to require long-term solutions following considerable planning. Yet, this does little to remedy the immediate challenges of access block within EDs. Given the associated costs of access block, it is therefore necessary to identify ways to improve patient flow in the ED, and thus, the interconnected departments.

One approach that holds promise for healthcare services is lean thinking [51]. Typically applied to private industries notably, manufacturing [63], [64], [44], [18], lean thinking aims to provide products or services 'in the most efficient manner by improving flow and eliminating waste from processes' [53] p.S39. This is achieved by understanding current processes, identifying areas for improvement, and implementing necessary change. The application of lean thinking to private industry has helped to improve productivity, reduce waste and lower costs [81] - and it is these strengths that hold promise for healthcare services.

The potential value of lean thinking for the healthcare sector is recognised by a number of federal and state governments. In the United Kingdom for instance, the National Health Service (NHS) has borrowed heavily from the Toyota System to 'improve quality (to deliver better and more timely patient care), to make working lives less stressful and more rewarding for staff and to boost efficiency and productivity (thereby pleasing politicians and taxpayers), all at the same time' [48] p.3. Similarly, Australian government policies allude to the role of process management principles - normally applied to the manufacturing industry, to the management of healthcare services [56]. This potentially includes the identification of value-adding processes as well as wastage.

One way to apply lean thinking is through the use of visual analytics. Visual analytics represents a marriage between computation, visual representation, and interactive thinking [83]. As Thomas and Cook [77] p. 10 explain:

visual analytics... [is] the science of analytical reasoning facilitated by interactive visual interfaces. People use visual analytics tools and techniques to synthesize information and derive insight from massive, dynamic, ambiguous, and 
often conflicting data; detect the expected and discover the unexpected; provide timely, defensible, and understandable assessments.

Techniques that are simultaneously visual and interactive can be helpful for four key reasons [20]. First, they can help users to understand complex data and situations where models alone are inadequate. Second, they readily detect 'trends and anomalies, evaluate hypotheses, and uncover unexpected connections' p.15. Third, through the use of contextual cues, they help the user to interpret the information he/she is presented. Finally, they encourage users to engage with and explore large datasets that might otherwise be daunting [82].

To demonstrate the way visual analytics can aid the management of healthcare services, this paper describes the application of visual analytics to a hospital department. Following a discussion of the role and operation of EDs, as well as issues affecting their performance, the paper outlines an approach to understand current departmental processes, identify areas for improvement, and pilot improved management strategies within a virtual environment. As such, this paper is methodological in scope and does not present findings associated with the implementation of the identified strategies.

\subsection{Role and Operation of Emergency Departments}

The term, 'emergency' implies an unexpected combination of circumstances that demands immediate action. In the medical setting, it involves an injury or illness that poses an immediate threat to patient wellbeing and requires rapid assistance or relief [38] - and perhaps, nowhere is this more apparent than in a hospital ED.

Emergency departments are highly visible, highly utilised, and highly valued by the community at large. For many individuals with acute health issues, they are the point of entry into the healthcare system - as such, the performance of EDs contributes to both patient and community wellbeing [13].

Emergency departments also have a vital role in shaping the care pathway a patient traverses through the hospital system - that is, patient flow [55]. Emergency departments assess individuals who present with a wide array of physical and mental health issues [25]; prioritise them accordingly; and usher them to appropriate departments and services. While seemingly efficient, the process typically involves many interactions between patient and different ED staff - interactions that are often separated by delays and extended waiting periods [46]. Such inefficiencies are discussed in the subsequent section.

\subsubsection{Factors that Influence Patient Flow}

Within an ED, patient flow is influenced by several factors. These include hospital policy, hospital resources, the nature of emergency healthcare, and the relationship between EDs and other hospital departments.

At a policy level, the operation of EDs in typically is guided by a triage system [24]. The system identifies clinical priorities to inform the provision of healthcare. Although formalised classification systems are sometimes lacking [4], [54], Australian hospitals typically use variations of the five triage categories endorsed by the Australasian College of Emergency Medicine [24]. As such, clinical decision-making therefore focuses on minimising risk - that is, possible health outcomes that have a negative impact on patient wellbeing [14], [15], [61], [74]. Once level of risk is determined, hospital resources, including staff, are deployed accordingly [47].

However, the limited availability of skilled hospital staff is a challenge confronting many Australian EDs [12]. Despite recent attempts to improve staff skill-base [13], these do not compensate for staff shortages, particularly among nurses [2]. This issue is further confounded by the challenge of orchestrating staff rosters, while complying with industrial legislation.

The reactive nature of emergency services also influences patient flow. Although the demand for emergency services is affected by extraneous factors, including seasonal change [2], EDs are expected to manage unexpected situations, including crises. This requires prompt access to equipment and competent staff [9].

Equally important for efficient patient flow are connections between EDs and subsequent hospital services required by the patient. Delayed services provided by supporting hospital departments, such as the imaging, pathology and/or pharmacy departments, have a limited ability to accommodate the healthcare needs of patients from the ED. This is demonstrated by the relationship between the ED and the diagnostic department.

Diagnostic resources are used to establish patient health status. They include imaging, radiology, sonography, and pathology, among others. When the availability of these resources is limited, bottlenecks can result in the ED where patients wait for tests they require. The consequences of this can be costly [32]. For instance, at a personal level, patients who may be redirected to alternative hospitals have delayed access to care; at a fiscal level, the costs associated with patient transfer are magnified; and at a political level, the public image of the healthcare system is tainted. 
Although the relationship between the emergency and diagnostic departments is important, most research on patient flow has focused on the surgical and outpatient departments [28], [29], [39]. This leaves much fertile ground for future research [32]. And given that diagnostic services are not exclusive to the ED, research that aims to improve patient flow to the diagnostic department would potentially benefit patient flow from other hospital departments.

\subsubsection{Initiatives to Improve the Emergency Department}

To improve patient flow in the hospital setting, a number of initiatives have been implemented to reduce access block [2], [17], [35]. In NSW, these include Patient Flow Units, and EDNA - the Emergency Department Network Access system.

Introduced in 2004, Patient Flow Units represent a centralised system that manages all patient admissions and transfer requests [11]. They work closely with other hospital departments - particularly the ED, to allocate beds efficiently and reduce access block. The potential of this initiative was demonstrated by one public hospital, which saw access block diminish by approximately 35 percent after using a centralised system for two months [21].

The Emergency Department Network Access system is an electronic system to disseminate information about hospital services to ambulances [24], [36]. Following patient triage, an ambulance officer inputs patient data into the system, and is then provided with information about appropriate hospital services. More specifically, the officer is informed of hospitals that are in close geographical proximity and that currently have the resources required to treat the patient; furthermore, the officer is given an approximate travel time to the hospital and the number of ambulances currently waiting at the hospital. This information helps ambulance officers to make an informed decision when seeking hospital services for patients. Once an officer selects a hospital, hospital personnel are notified electronically; they are also advised of the patient's condition and the estimated time of arrival.

Although promising, these (and other) initiatives have had limited affect on access block [for additional strategies, see 17], [68]. Consequently, hospital managers are compelled to experiment with different strategies, some of which might be futile.

Process modelling and simulation represent one way to circumvent potentially futile experimentation. By mapping hospital processes and patient flow within a virtual environment, it is possible to identify opportunities for improvement, and trial innovative strategies without risking the operation of the hospital, patient welfare, or the hospital budget. This holds particular promise for settings like EDs that are highly uncertain and require rapid and effective decisions.

\subsection{Process Modelling and Simulation}

Process modelling is a business process management activity to visually represent a current situation in an effort to fully understand and improve processes to gain efficiencies [49]. It often involves the use of information technology to create visual process maps such as activity diagrams, flowcharts, Program (or Project) Evaluation and Review Technique (PERT) diagrams, and the like. Coined by Williams [80], Business Process Modeling (BPM) is premised on the belief that techniques for understanding physical control systems can be equally valuable for understanding business processes.

Similarly, process modelling has been applied to healthcare settings. With the push for delivering high quality care, while reducing care costs, process modelling has been used to manage and improve workflows in healthcare [8]. For example, BPM was used to assess inpatient transport services in an effort to reduce occasions of service within the NSW ambulance service [58]. However, the academic literature is devoid of papers on tangible improvements as a direct result of BPM in healthcare institutions.

Process modelling generally commences with data mining - that is, the analysis of large-scale datasets from different sources. The purpose of data mining is to identify key patterns and trends, and thus understand macro processes reflected in the datasets [43]. This might include patterns of service delivery, production, and/or consumer behaviour. Process mining is then conducted to identify patterns and trends at a micro level. Event logs are used to analyse business processes and understand the minutiae of operational practices [79]. And it is this understanding that allows problem areas to be identified, and improvement strategies to be simulated.

Simulation is a versatile way to understand and optimise the operation of systems [75], [50]. It can also help to visualise the impact of local decisions on entire systems. Macro and micro processes can be portrayed and manipulated, and the real effects of such manipulation can be surmised.

One approach to simulation is through visual analytics. Visual analytics is the science of methodical calculation, which is facilitated by interactive visual presentation. Its strength is its pragmatism. Using graphical computer software, macro and micro processes can be depicted and modified, and subsequent effects can be surmised. As such, visual analytics provides predictive value, allowing users to experiment with innovative change without the need to pilot such change in vivo. As Thomas [76] describes: 
People use visual analytics tools and techniques to synthesize information and derive insight from massive, dynamic, ambiguous, and often conflicting data; detect the expected and discover the unexpected; provide timely, defensible, and understandable assessments; and communicate assessment effectively for action p.104.

\subsection{Visual Analytics in Healthcare}

Given its practical value, visual analytics might help to improve patient flow within EDs. Through its ability to rapidly vary the factors that affect patient flow, and model change within the department, visual analytics can visually present and trial a number of improvement strategies without cost or inconvenience to staff, patients, or the hospital as a whole.

Although potentially useful to improve patient flow, the use of visual analytics in healthcare settings is not without problem. The key challenge pertains to data collection. Visual analytics requires extensive and comprehensive datasets - however, hospital data can be difficult to access [19]. There are two key reasons for this - namely, the confidential nature of datasets pertaining to the operation of a hospital and/or patients; as well as the size and complexity of the datasets, often rendering them incomplete.

Yet, even if extensive and comprehensive datasets are accessible, there is some concern that healthcare settings are not conducive to process simulation. Jenkins and colleagues [47] for instance, argue that - relative to the manufacturing sector, where principles of lean thinking are typically applied - healthcare settings are complex; consequently, validating and verifying simulation models can be difficult.

Despite these challenges, hospitals - particularly EDs, represent appropriate settings to use visual analytics to model and simulate processes. This is primarily because of two reasons. First, given their role, the planning and scheduling of hospital beds, equipment and personnel within EDs are often extemporised - this in turn hinders attempts to evaluate alternative management processes. Second, consequent to policy directives, EDs are generating additional types and increasing quantities of data [57]. These data can thus be used to make patient flow issues visible, and trial innovative management strategies.

To demonstrate the potential role of visual analytics in healthcare, a case study is presented. As an example of the NSW public health system, data collected from a hospital department is integrated using a visual analytics software program to understand complex hospital processes, identify areas for improvement, and simulate innovative management strategies.

\section{Methodology}

\subsection{Case Study}

The department to which visual analytics was applied is situated in a NSW public hospital that serves a highly populated and ethnically diverse community [72]. The region is also characterised by high levels of unemployment and encompasses nine of the ten lowest socio-economic communities within metropolitan Sydney.

Serving a highly populated community, the ED has experienced significant increases in demand [73]. From 2005-06 to 2006-07, the Area Health Service witnessed an increase of ED presentations by 10.87 percent; an increase of ED admissions by 9.5 percent; the highest ambulance presentations in the state; and a rise in the number of primary care patients from 22 to 28 percent.

Despite improved performance within the area health service to which it belongs, such improvement was not always demonstrated within the ED. For instance, from 2005-06 to 2006-07, a mandatory hospital report reveals that the percentage of admissions transferred from the ED within eight hours [59] improved from 67 to 76 percent; however, figures from the hospital reveal a decline of these admissions from 66 to 61 percent - the lowest of all hospitals within the area.

With increased demand, the ED experienced recurrent access blocks. Although hospital data was very limited, access block was indicated by hospital personnel and observed by the researchers. Yet, through extended consultation and observation, it also became apparent that one source of access block was the adjoining sonography department. Delays in conducting ultrasounds - be they on inpatients, outpatients, or patients from the ED, strained the ED further. For this reason, hospital personnel identified the sonography department as the preferred site for the study.

\subsection{Method}

Following approval from both the relevant academic and hospital research ethics committees, BPM and visual analytics were used to map the layout and processes of the sonography department, identify improvement areas, and simulate innovative strategies to improve patient flow. To effectively manage the wealth of data required for the 
study, visual analytics software - namely, Tecnomatix Plant Simulation ${ }^{\circledR}$, was used to integrate data about departmental functions, resources, events, relationships between components, communication links, and information flow.

Tecnomatix Plant Simulation® software is a tool that facilitates discrete event simulation and the creation of digital models of logistic systems [70]. This allows users to investigate system characteristics; test modifications without disrupting the system; and identify ways to optimise system performance.

For ease of readability, the use of BPM and visual analytics is presented in a staged manner. However, given the complexities of hospital-based research the process did not always proceed in a linear fashion.

\subsubsection{Collecting process data}

The first stage of the study involved developing strategies and automated procedures for creating event logs for all components within departmental processes. The event logs included information about the type of process; the rooms and equipment involved in the process; the staff and skill-based required; and the timeframe that all identified resources were needed. Although initially sourced from existing hospital datasets, the information was verified through observation of the process over a seven-month period, as well as interviews with all five sonography department staff - this included senior personnel and subordinates. Guided by a semi-structured interview schedule, the researchers invited the staff members to provide their views about patient flow within the department, factors that helped and hindered this, as well as ways to improve patient flow.

The first stage of the study also involved the identification of key measurement points, such as room and equipment capacity, bookings procedure, patient scheduling, observed wait times, procedure times, patient case-mix, as well as human resources. These were used to determine the outcome measures, including average wait time, number of patients treated, number of ED patients, number of inpatients and outpatients, average overtime worked by staff, room use, and the utilisation of sonographers.

\subsubsection{Constructing process clusters}

Following their identification, departmental processes that shared similar resource demands were grouped into clusters. Using event logs, process mining premised on BPM was then performed to detect micro trends [79], and thus, opportunities to manipulate and control the processes. The event logs consisted of information pertaining to time of patient arrival to, and departure from, the department; triage rating; and sequence of events in the department. Process mining helped to identify and extract the necessary information from large datasets, and represent identified processes through a network model.

\subsubsection{Monitoring key measurement points}

To determine the extent of variability within the identified departmental processes, the key measurement points were monitored for three months. This involved observing patient flow within the department and collecting data pertaining to outpatient wait times over a two-week period. It was important to collect this data because they were not part of existing hospital datasets, and they were needed to understand the performance of the department, as well as key decision points that influenced this performance. The two-week timeframe was determined in consultation with hospital personnel who deemed it sufficient to capture the information required for the scope of the study. For all other data, the three-month timeframe was selected because, according to the clinicians, this would be sufficient time to adequately capture typical departmental processes.

\subsubsection{Constructing a virtual model}

Using Tecnomatix Plant Simulation ${ }^{\circledR}$ software, the process clusters and data on the key measurement points were integrated to construct a virtual model of the sonography department. Based on an algorithm [50], the model depicted actual processes and helped to understand departmental (in)efficiencies using statistical outputs utilisation of space, equipment and staff. Given the complexity associated with the algorithm, further detail can be found elsewhere [37].

Using the software, the virtual model was then reformed into an interactive image of the sonography department. The software helped to identify core business processes in relation to the scheduling of patients, room utilisation, and the allocation of appropriate personnel. The core business processes were simulated (graphically), illustrating actual workflow, as well as identify opportunities to improve patient flow. A screenshot of the department is shown (see Figure 1). 


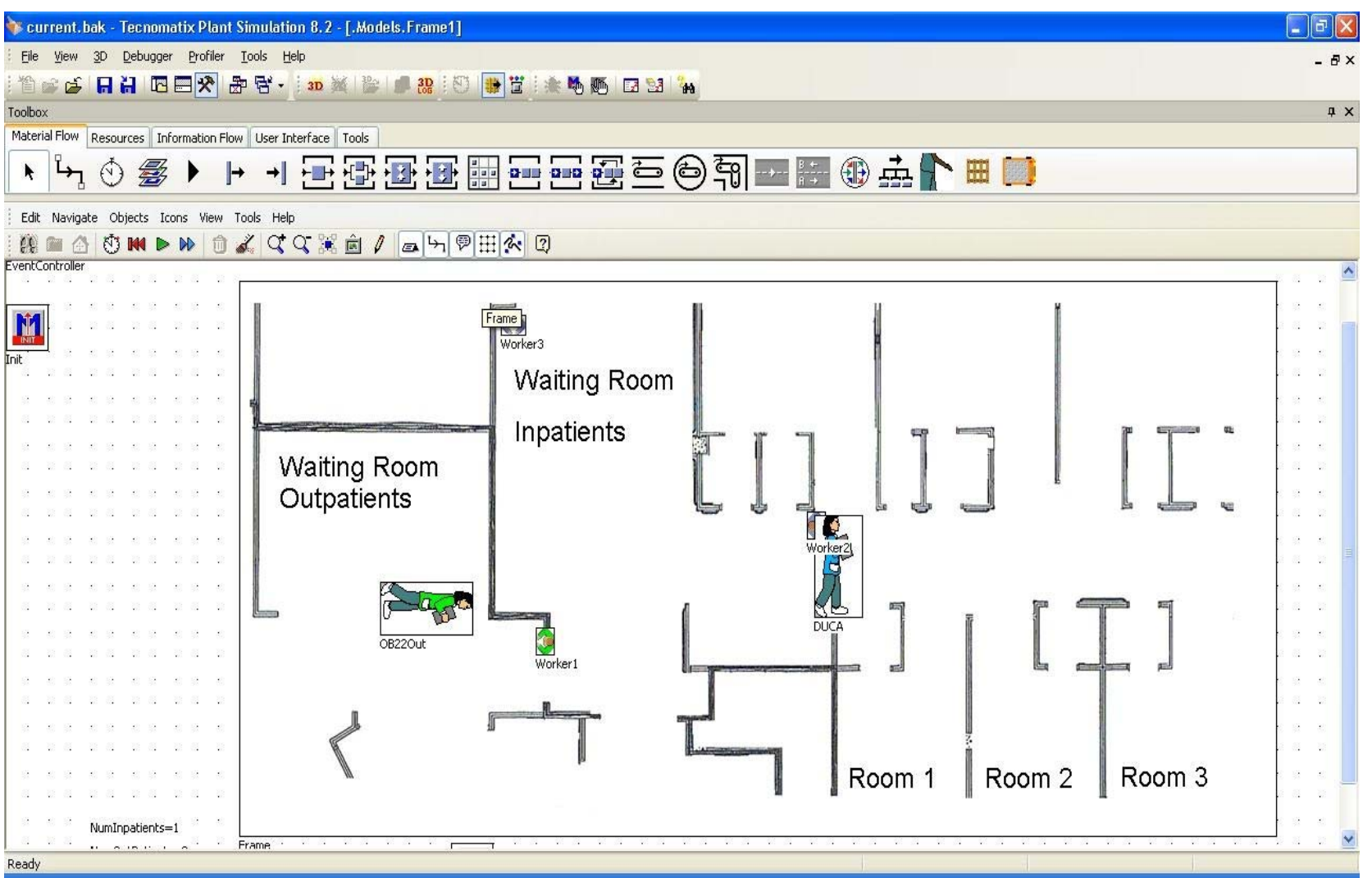

Figure 1: Current Scheduling Practices in the Sonography Department

\subsubsection{Validation}

Although the software provided objective representations of actual processes, it was important to invite sonography department personnel to validate the representations. The aim of this was two-fold - first, to gauge the perceived face validity of the model among those who might potentially use it, and second, to demonstrate bona fide collaboration to key stakeholders - namely, hospital staff. For these reasons, approximately twenty staff members were consulted from both the imaging and emergency departments, including clinicians, managers and sonographers. They were asked to verify the model for authenticity and suggest solutions that could be simulated. Staff members were also asked to voice the factors that would help or hinder its use within the department.

Collectively, those consulted indicated that the model was a sound representation of processes within the sonography department. Further to this, as demonstrated by the model, the hospital personnel identified poor room utilisation as a hindrance to patient flow. This feedback helps top validate the model and its representation of departmental processes.

\subsubsection{Simulating improved processes}

Once validated, the model was then manipulated to identify ways to improve patient flow. By varying information pertaining to patient-scheduling practices, staff numbers, and room allocations, process logs were simulated and compared to those of actual processes (for the same timeframe). This helped to gauge the accuracy of the simulations and refine them accordingly. For example, one suggestion was to change scheduling time per procedure from 60-minute intervals to 50-minute intervals. Table 1 depicts the simulated outcome for this change. 
Table 1: Simulated outcome of modifying scheduling time per procedure

\begin{tabular}{|l|c|c|}
\hline \multicolumn{1}{|c|}{ Outcome measure } & $\begin{array}{l}\text { Current situation: } \\
60 \text {-minute interval }\end{array}$ & $\begin{array}{l}\text { Modified situation: } \\
50 \text {-minute interval }\end{array}$ \\
\hline $\begin{array}{l}\text { Waiting time per patient for } \\
\text { procedure (mins) }\end{array}$ & $04: 39.0$ & $11: 22.7$ \\
\hline $\begin{array}{l}\text { Total patients seen by departmental } \\
\text { staff }\end{array}$ & 3,927 & 4,488 \\
\hline Inpatients seen by departmental staff & 1,784 & 2,042 \\
\hline $\begin{array}{l}\text { Outpatients seen by departmental } \\
\text { staff }\end{array}$ & 994 & 1,137 \\
\hline $\begin{array}{l}\text { Emergency patients seen by } \\
\text { departmental staff }\end{array}$ & 1,149 & $12: 37.5$ \\
\hline Staff overtime (mins) & $08: 43.0$ & $61 \%$ \\
\hline Room use & $54 \%$ & $14 \%$ \\
\hline Room use including weekends & $13 \%$ & $96 \%$ \\
\hline Utilisation of sonographers & $85 \%$ & \\
\hline
\end{tabular}

\subsubsection{Implementation and evaluation}

Although the simulated models are not (yet) applied in the case study, the final stage would involve the implementation of those deemed most suitable, at the discretion of the hospital. It would also involve a period of evaluation to determine whether access block had been affected by the modifications to process. An evaluation of the identified improvement strategies is currently underway with the hospital.

\section{Discussion}

Consequent to the disparity between supply and demand, the healthcare system in many Western nations is far from ideal [52], [60], [10], [13]; access block is symptomatic of this [2], [17]. Although access block might be addressed by attending to a number of systemic issues [5], [30], [35], [31], [62], [41], [33], [45], [42], [84], [23], [69] there is an immediate need to improve patient flow within the hospital system. Failure to address this problem potentially jeopardises healthcare services and the health of patients [71], [34], [78], [26], [16], [66], [27], [67].

This paper presents one option to inform strategic decision-making, and as such, the potential to improve patient flow. Using visual analytics within a sonography department, the study reveals the way in which complex processes within a hospital department can be understood; the way areas for improvement can be identified; and the way viable options to improve these areas can be simulated. Although this paper is methodological in scope, and as such, does not present evidence of improved efficiencies, the interconnected nature of hospital departments [40] would suggest that improved efficiencies in one department is likely to have beneficial effects on surrounding departments - this includes the ED.

In addition to the potential for greater efficiencies, visual analytics offers the hospital setting two further benefits. First, change can be piloted without the need for environmental (including policy) change. Second, visual analytics allows hospital staff to observe the potential benefits associated with an altered process, which in turn, can increase confidence.

This methodological paper offers two key lessons to those interested in visual analytics. First, as a field that attracts the interest of multiple disciplines, ontological divergence is a potential hazard within a team of visual analysts. Team members who are steadfast to particular paradigms might struggle to compromise their position and widen their blinkered view. For this reason, the creation of shared understandings and shared interpretations are essential for the success of the visual analytic project. In addition to extensive discussion about the research problem and the appropriate methodology, this requires consideration of the disciplines that should be represented within the team. For instance, the researchers involved in this study represented mathematics, computing, operations management, business systems, and health management.

Second, visual analytics is highly contextual; for this reason, continued engagement with stakeholders is pivotal. In an overstretched setting like a hospital, where time, resources and personnel are limited, the presence of external (read, foreign) researchers can be taxing, if not fatiguing to hospital personnel. For this reason, research etiquette should be brought to the fore. This might include enlisting the support of local opinion leaders; incorporating into the project multiple opportunities for all key stakeholders to inform the seven aforesaid stages of the project; as well as the provision of interim reports to notify stakeholders of progress to date [22].

Visual analytics represents an innovative approach to inform departmental changes that may improve patient flow in hospital settings. It portrays actual processes in a novel way, regardless of complexity or the parameters involved; and it accentuates opportunities for improvement. By manipulating critical parameters, animated simulation can test 
a range of improvement options and present the results in a visual manner that is readily interpreted by the time-poor hospital manager. Opportunities can then be tested in real hospital settings with greater confidence of their effectiveness. Considering the prime role of EDs, it is essential to develop and provide the means that optimise their processes.

\section{References}

[1] ACEM (Australasian College for Emergency Medicine), Policy document: Standard terminology, Emergency Medicine, vol. 14, pp. 337-340, 2002.

[2] ACEM (Australasian College for Emergency Medicine), Access block and overcrowding in emergency departments, ACEM (Australasian College for Emergency Medicine), West Melbourne, VIC, April 2004.

[3] ACEP (American College of Emergency Physicians) Task Force, Emergency department crowding: High-impact solutions, ACEP (American College of Emergency Physicians), Dallas, TX, April 2008.

[4] Acute Surgical Services Working Party, Report, Royal Australasian College of Surgeons, Sydney, NSWNov. 2004.

[5] AlHW (Australian Institute of Health and Welfare), Australian hospital statistics 2003-04, AlHW (Australian Institute of Health and Welfare), Canberra, ACT 23, 2005.

[6] AlHW (Australian Institute of Health and Welfare), Australian hospital statistics 2005-06, Canberra, ACT: AlHW (Australian Institute of Health and Welfare), 2007.

[7] AlHW (Australian Institute of Health and Welfare), Australian hospital statistics 2006-07, AlHW (Australian Institute of Health and Welfare), Canberra, ACT HSE 55, May 2008.

[8] K. Anyanwu, A. Sheth, J. Cardoso, J. Miller, and K. Kochut, Healthcare enterprise process development and integration, Journal of Research and Practice in Information Technology, vol. 35, pp. 83-98, 2003.

[9] L. Argote, Input uncertainty and organizational coordination in hospital emergency units, Administrative Science Quarterly, vol. 27, pp. 420-434, 1982.

[10] K. Benson, Code red: Hospitals in crisis, in Sydney Morning Herald. vol. 2009 Sydney, NSW: Fairfax Digital, 2008.

[11] M. Berry and B. Reid, The patient flow hot line, in Clinical Services Redesign Program. vol. 2009 Sydney, NSW: Sydney West Area Health Service, 2006.

[12] R. J. Blendon, C. Schoen, C. M. DesRoches, R. Osborn, K. Zapert, and E. Raleigh, Confronting competing demands to improve quality: A five-country hospital survey, Health Affairs, vol. 23, pp. 119-135, 2004.

[13] Booz Allen Hamilton, Key drivers of demand in the emergency department: A hypothesis driven approach to analyse demand and supply, NSW Health, Sydney, NSW, December 2007.

[14] British Medical Association, The BMA guide to living with risk. London, UK: Penguin, 1990.

[15] B. L. J. Brown, Risk management for hospitals: A practical approach. Germantown, Maryland: Aspen Systems Corporation, 1979.

[16] P. Cameron, President's message, in Your Direction. vol. 2 Melbourne, VIC: ACEM (Australasian College for Emergency Medicine), 2001, pp. 2-3.

[17] P. A. Cameron and D. A. Campbell, Access block: Problems and progress, Medical Journal of Australia, vol. 178, pp. 99-100, 2003.

[18] S. W. Carleysmith, A. M. Dufton, and K. D. Altria, Implementing lean sigma in pharmaceutical research and development: a review by practitioners, R\&D Management, vol. 39, pp. 95-106, December 2008.

[19] R. Cleary, R. Beard, J. Coles, B. Devlin, A. Hopkins, D. Schumacher, and I. Wickings, Comparative hospital databases: Value for management and quality, Quality and Safety in Health Care, vol. 3, pp. 3-10, 1994.

[20] K. Cook, R. Earnshaw, and J. Stasko, Discovering the unexpected, IEEE (Institute of Electrical and Electronics Engineers) Computer Graphics and Applications, pp. 15-19, September/October 2007.

[21] M. Coombes, Patient flow project RPA: Sydney South West Area Health Service. vol. 2009 Chatswood, NSW: ARCHI (Australian Resource Centre for Healthcare Innovations), 2006.

[22] A. Dadich and K. Muir, Tricks of the trade in community mental health research: Working with mental health services and clients, Evaluation \& the Health Professions, vol. 32, pp. 38-58, March 2009.

[23] S. Day, K. Alford, D. Dunt, S. Peacock, L. Gurrin, and D. Voaklander, Strengthening Medicare: Will increasing the bulk-billing rate and supply of general practitioners increase access to Medicare-funded general practitioner services and does rurality matter?, Australia and New Zealand Health Policy, vol. 2, p. 18, 2005.

[24] Department of Health and Ageing, The state of our public hospitals: June 2005 report, Commonwealth of Australia, Canberra, ACT, 2005.

[25] Department of Health and Ageing, The state of our public hospitals: June 2007 report, Commonwealth of Australia, Canberra, ACT, 2007.

[26] R. Derlet, Overcrowding in emergency departments: Increased demand and decreased capacity, Annals of Emergency Medicine, vol. 39, pp. 430-432, 2002.

[27] R. W. Derlet and J. R. Richards, Overcrowding in the nation's emergency departments: Complex causes and disturbing effects, Annals of Emergency Medicine, vol. 35, pp. 63-68, 2000.

[28] F. Dexter and R. H. Epstein, Operating room efficiency and scheduling, Current Opinion in Anaesthesiology, vol. 18 , pp. $195-198,2005$

[29] L. Doolan, Operating room utilisation management, in Access to surgery, P. Donnelly and L. Wadhwa, Eds. Brisbane, QLD: University of Queensland, 1997, pp. 43-52.

[30] S. J. Duckett, The Australian health care system, Third ed. Sydney, NSW: Oxford University Press, 2007. 
[31] S. J. Duckett, M. Coory, and K. Sketcher-Baker, Identifying variations in quality of care in Queensland hospitals, Medical Journal of Australia, vol. 187, pp. 571-575, 2007.

[32] S. G. Elkhuizen, J. R. C. van Sambeek, E. W. Hans, K. Krabbendam, and P. J. M. Bakker, Applying the variety reduction principle to management of ancillary services, Health Care Management Review, vol. 32, pp. 37-45, 2007.

[33] A. Elliot, The decline in bulk billing: Explanations and implications, Commonwealth of Australia, Canberra, ACT 3 2002-2003, 2002.

[34] C. A. Erikson, M. McErlean, J. M. Bartfield, and V. P. Verdile, Relationship between maloccurences and ED census and staffing, Academic Emergency Medicine, vol. 8, p. 499, 2001.

[35] D. M. Fatovich and R. L. Hirsch, Entry overload, emergency department overcrowding, and ambulance bypass, Emergency Medicine Journal, vol. 20, pp. 406-409, September 2003.

[36] D. M. Fatovich, Y. Nagree, and P. Sprivulis, Access block causes emergency department overcrowding and ambulance diversion in Perth, Western Australia, Emergency Medicine Journal, vol. 22, pp. 351-354, 2005.

[37] J. A. Fitzgerald, F. Cornelissen, O. Camacho-Duarte, A. Dadich, P. Samaranayake, and J. Vancikova, Health management innovation: Improving efficiencies in the emergency department via the modelling of work processes, CInIS (Centre for Industry and Innovation Studies), College of Business, University of Western Sydney, Sydney, NSW, 2009.

[38] J. A. Fitzgerald, M. Lum, and A. Dadich, How can human technologies improve decision-making practices in the operating theatre?, in 4th Health Care Technology Management Conference, Aalborg, Denmark, 2005.

[39] J. A. Fitzgerald, M. Lum, and L. Kippist, Operating theatre bottlenecks: How are decisions about emergency theatre schedules made, in 5th International CINet Conference, Sydney, NSW, 2004.

[40] J. A. Fitzgerald and T. Sloan, Workflow issues in imaging department, CInIS (Centre for Industry and Innovation Studies), University of Western Sydney, Parramatta, NSW, 2008.

[41] G. Ford, The role of the emergency department as a 'safety net', Health Issues, vol. 73, pp. 29-32, 2002.

[42] D. Griggs and C. Atkins, The bulk billing crisis: A Victorian perspective, VCOSS (Victorian Council of Social Service), Melbourne, VIC, 2004.

[43] J. Han and M. Kamber, Data mining: Concepts and techniques, Second ed. San Francisco: Morgan Kaufmann Publishers, 2005.

[44] P. Hines and S. Lethbridge, New development: Creating a lean university, Public Money \& Management, vol. 28, pp. 53-56, Dec. 2007.

[45] S. Hopkins and N. Speed, The decline in 'free' general practitioner care in Australia: Reason and repercussions, Health Policy, vol. 73, pp. 316-329, 2005.

[46] Hunter New England Area Health Service, Improving patient flow in the Lower Hunter winter '07 cost effectively, Hunter New England Area Health Service, Newcastle, NSW2008.

[47] R. Jenkins, Y. Deshpande, and G. Davison, Verification and validation and complex environments: A study in service sector, in Winter Simulation Conference Washington D.C.: IEEE (Institute of Electrical and Electronics Engineers) Computer Society Press, 1998.

[48] D. Jones and A. Mitchell, Lean thinking for the NHS, NHS Confederation, London, 2006.

[49] M. Laguna and J. Marklund, Business process modeling, simulation, and design. Upper Saddle River, NJ: Prentice Hall, 2005.

[50] A. M. Law and W. D. Kelton, Simulation modeling and analysis, Third ed. New York, NY: McGraw-Hill, 2000.

[51] M. Lindgaard Laursen, F. Gertsen, and J. Johansen, Applying lean thinking in hospitals: Exploring implementation difficulties, Center for Industrial Production, Aalborg University, Aalborg, The Netherlands, 2003.

[52] M. McKee and J. Healy, Hospitals in a changing Europe, in European Observatory on Health Care Systems, J. Figueras, M. McKee, E. Mossialos, and R. B. Saltman, Eds. Buckingham, UK: Open University Press, 2002.

[53] NA, Health services under siege: The case for clinical process redesign, Medical Journal of Australia, vol. 188, p. S39, March 2008.

[54] NSW Health, NSW Health operating theatre management project report, NSW Health, Sydney, NSW2002.

[55] NSW Health, Waiting time and booked patient management: Technical guidelines, NSW Health, Sydney, NSW, September 2003

[56] NSW Health, Patient safety and clinical quality program: First report on incident management in the NSW public health system 2003-2004, NSW Health, Sydney, NSW, January 2005.

[57] NSW Health, Policy directive: Data collections - Process for approval of new or modified, NSW Health, Sydney, NSW PD2005_155, January 2005.

[58] NSW Health, Delivering safe, effective and efficient inpatient transport service. vol. 2009 Sydney, NSW: NSW Health, 2007.

[59] NSW Health, Performance reports. vol. 2009 Sydney, NSW: NSW Health, 2008

[60] R. Paoloni and D. Fowler, Total access block time: A comprehensive and intuitive way to measure the total effect of access block on the emergency department, Emergency Medicine Australasia, vol. 20, pp. 16-22, 2008.

[61] Practising Law Institute, Risk management for hospitals and health care institutions, Practising Law Institute H43887, March/May 1979.

[62] RACS (Royal Australasian College of Surgeons), Acute surgical services working party: Report, RACS (Royal Australasian College of Surgeons), Sydney, NSW, November 2004.

[63] Z. Radnor and R. Boaden, Lean in public services: Panacea or paradox?, Public Money \& Management, vol. 28, pp. 3-7, February 2008.

[64] D. Reinertsen and L. Shaeffer, The logic of lean, Research Technology Management, vol. 48, p. 52, July/August 2005. 
[65] D. Richardson, Access block point prevalence survey, ACEM (Australasian College for Emergency Medicine), West Melbourne, VIC, September 2008.

[66] D. B. Richardson, Association of access block with decreased ED performance, Academic Emergency Medicine, vol. 8, pp. 575-576, 2001.

[67] D. B. Richardson, The access-block effect: Relationship between delay to reaching an inpatient bed and inpatient length of stay, Medical Journal of Australia, vol. 177, pp. 492-495, 2002.

[68] D. B. Richardson, E. R. Ruffin, J. K. Hooper, R. J. H. Hammett, B. G. Robinson, R. H. Ashby, D. M. Fatovich, P. A. Cameron, D. A. Campbell, and K. N. Hill, Responses to access block in Australia, Medical Journal of Australia, vol. 178, pp. 103-111, 2003.

[69] E. Savage and G. Jones, An analysis of the General Practice Access Scheme on GP incomes, bulk billing and consumer copayments, Australian Economic Review, vol. 37, pp. 31-40, 2004.

[70] Siemens, Plant simulation: Product overview. vol. 2009 Plano, TX: Siemens, 2009.

[71] South Australian Coroner, Report on the findings of the inquest Vassallo V. vol. 28/2002, no. 2841/2000, Courts Administration Authority, 2003.

[72] SSWAHS (Sydney South West Area Health Service), SSWAHS statutory annual report 06/07, S. S. S. W. A. H. Service), Ed.: SSWAHS (Sydney South West Area Health Service) Public Affairs and Marketing, 2007, p. 201.

[73] SSWAHS (Sydney South West Area Health Service), SSWAHS year in review 06/07, S. S. S. W. A. H. Service), Ed. Sydney, NSW: SSWAHS (Sydney South West Area Health Service) Public Affairs and Marketing, 2007.

[74] Standards Australia/Standards New Zealand, Handbook: Risk management guidelines companion to AS/NZS 4360:2004, Standards Australia/Standards New Zealand, Sydney, NSW HB 436:2004, 2004.

[75] J. Thomas and K. Cook, Illuminating the path: Research and development agenda for visual analytics. Richland, WA: IEEE (Institute of Electrical and Electronics Engineers), 2005.

[76] J. J. Thomas, Visual analytics: Why now?, Information Visualization, vol. 6, pp. 104-106, Spring 2007.

[77] J. J. Thomas and K. A. Cook, A visual analytics agenda, IEEE (Institute of Electrical and Electronics Engineers) Computer Graphics and Applications, pp. 10-13, January/February 2006.

[78] J. Thompson, Coroners and lack of emergency resources, Journal of Emergency Medicine, vol. 17, pp. 541-542, 1999.

[79] W. van der Aalst, T. Weijters, and L. Maruster, Workflow mining: Discovering process models from event logs, IEEE (Institute of Electrical and Electronics Engineers) Transactions on Knowledge and Data Engineering, vol. 16, pp. 1128-1142, 2004.

[80] S. Williams, Business process modeling improves administrative control, Automation, pp. 44-50, Dec. 1967.

[81] J. P. Womack and D. T. Jones, Lean thinking. London: Simon and Schuster, 1996.

[82] P. C. Wong, S. J. Rose, G. J. Chin, D. A. Frincke, R. May, C. Posse, A. Sanfilippo, and J. Thomas, Walking the path: A new journey to explore and discover through visual analytics, Information Visualization, vol. 5, pp. 237249, Winter 2006.

[83] P. C. Wong and J. Thomas, Visual analytics, IEEE (Institute of Electrical and Electronics Engineers) Computer Graphics and Applications, vol. 24, pp. 20-21, September/October 2004.

[84] G. Young, B. White, J. Burgess, D. Berlowitz, M. Meterko, M. Guldin, and B. Bokhour, Conceptual issues in the design and implementation of pay-for-quality programs, American Journal of Medical Quality, vol. 20, pp. 144150, 2005. 